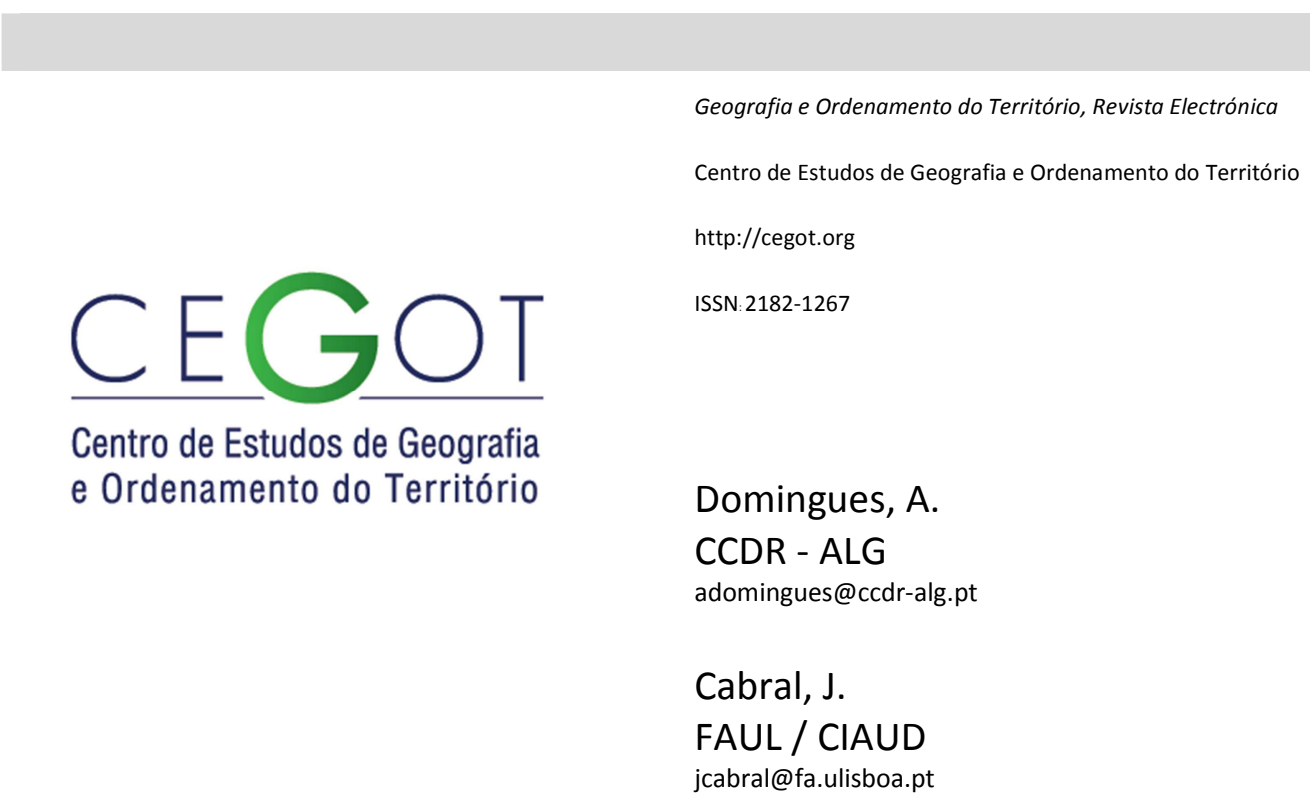

\title{
Áreas para o acolhimento das actividades empresariais no Algarve. Estratégias e instrumentos de gestão territorial
}

Referência: Domingues, A.; Cabral, J. (2014). Áreas para o acolhimento das actividades empresariais no Algarve. Estratégias e instrumentos de gestão territorial. Revista de Geografia e Ordenamento do Território (GOT), n.o 5 (junho). Centro de Estudos de Geografia e Ordenamento do Território, p. 67-91

\section{Resumo}

O artigo analisa os conteúdos dos documentos estratégicos para a Região do Algarve, as orientações fornecidas pelos planos de escala supra-municipal e a transposição destas para os instrumentos de gestão territorial, no que respeita à implementação de áreas para o acolhimento empresarial. Decorridas já duas décadas sobre a entrada em vigor do Plano Regional de Ordenamento do Território (PROT), os subsequentes planos directores municipais e a revisão do PROT, procura-se caracterizar o conteúdo das estratégias regionais e avaliar a eficácia dos instrumentos de gestão territorial que lhes dariam expressão. A análise efectuada permite adiantar que persistem quadros estratégicos vagos e pouco assertivos, frequentemente fundados em diagnósticos superficiais, que os instrumentos de gestão territorial não têm, regra geral, veiculado qualquer estratégia concertada, mas também que existem "modelos" de implementação e de funcionamento de áreas de acolhimento empresarial, fruto de iniciativas isoladas, que se apresentam como casos de sucesso e de recomendável adopção, para as entidades públicas ou privadas, em territórios mais dinâmicos ou mais periféricos. 
Palavras -chave: Áreas de acolhimento empresarial; ordenamento do território; espaços industriais; desenvolvimento regional; Algarve

\begin{abstract}
Economic development areas in Algarve: the efficacy of the strategies of territorial planning instruments or the maintenance of previous logics.

The article looks into the contents of strategic documents for the Region of the Algarve, the orientations given by the supra-municipal plans and the way these orientations are reflected into the territorial planning instruments in terms of the implementation of economic development areas. After two decades since the Regional Plan (PROT) was issued, the succeeding municipal master plans and the revision of the PROT, the article aims to characterise the contents of the regional strategies and to evaluate the efficacy of the territorial planning instruments expressing these strategies. The analysis suggests that vague and inadequate assertive strategic objectives still persist based on superficial diagnosis. Thus, territorial planning instruments are not based on concerted strategies. Yet, models for the implementation and functioning of economic development areas do exist, resulting from isolated initiatives, which can be seen as success stories to be adopted by public and private entities, in more dynamic or peripheral territories.
\end{abstract}

Keywords: Economic development areas; territorial planning; industrial spaces; regional development; Algarve.

\title{
1. Introdução
}

Passados mais de 20 anos desde a entrada em vigor do Plano Regional de Ordenamento do Território do Algarve (PROT 1991), e quase outros tantos desde a publicação da grande maioria dos planos directores municipais (PDM) dos 16 municípios da Região, considerou-se pertinente analisar os conteúdos e as directrizes dos documentos estratégicos, e as orientações emanadas dos planos de escala supra-municipal, assim como as interpretações e as transposições que delas fizeram os instrumentos de gestão territorial (IGT) em matéria de implementação de áreas para o acolhimento de actividades empresariais. Estas áreas correspondem aos espaços definidos nos instrumentos de gestão territorial (sobretudo nos PDM) expressamente para a instalação de unidades industriais, grandes estabelecimentos comerciais, operadores logísticos e serviços relacionados com as actividades produtivas.

A pouca clareza e assertividade dos documentos orientadores para aquelas actividades, que contribuiu em grande medida para uma actuação dos municípios pautada pela inconsistência, incoerência e ausência de articulação num plano regional (que as 
actividades empresariais exigem) teve, e tem, como resultado no território e no sector empresarial, uma eficácia muito aquém da visada pelos postulados enunciados pelas estratégias. Todavia, há casos (poucos) de sucesso, com reconhecimento fora da Região, fruto de iniciativas isoladas (públicas e privadas), que se configuram como "modelos" adoptáveis a outros contextos territoriais, mais ou menos dinâmicos ou periféricos.

Um primeiro esforço de monitorização das áreas empresariais no Algarve teve início em 2009. A CCDR Algarve disponibilizou a plataforma www.algarveacolhe.com, para divulgar junto de potenciais investidores na Região a oferta de terrenos e instalações, para venda ou aluguer, nos espaços definidos pelos IGT da Região do Algarve para usos empresariais. Pretendeu-se colmatar a ausência de informação sobre a oferta regional para fins empresariais, inibidora da concretização das intenções descritas nos documentos estratégicos para a Região, que referem a necessidade de diversificar a base económica, demasiadamente assente na construção / imobiliária / turismo.

Este projecto permitiu estruturar os elementos essenciais para efectuar uma análise em duas vertentes: i) conhecer, em termos quantitativos e qualitativos, o tecido empresarial da Região; e ii) observando a dinâmica de instalação das empresas, avaliar a aderência aos objectivos traçados nos documentos da estratégia de desenvolvimento regional veiculados pelos IGT. Parte-se da tese de que os objectivos do PROT 91 (DR n. 11/91, de 21 de Março) quanto à dinamização e desenvolvimento de um sector produtivo regional forte e inovador, não foram ainda alcançados. Constata-se também que os IGT em vigor, que supostamente traduziriam as orientações da estratégia regional, não foram eficazes na implementação das intenções que tinham subjacentes quanto à distribuição e localização das áreas para fins empresariais. Porém, é incorrecto inferir que a responsabilidade caberá apenas aos IGT, por não terem "cumprido" as orientações dos documentos estratégicos ou dos planos supramunicipais ou regionais. Como se tentará demonstrar, não só os IGT (administração local) pouco atenderam aos respectivos enquadramentos regionais (ou mesmo sub-regionais), como também as próprias estratégias não continham linhas programáticas e de operacionalização e, sobretudo, não avaliaram as estratégias anteriores. Ou seja, no caso em análise, os enquadramentos estratégicos que se vêm sobrepondo partem, persistentemente, de uma ausência de avaliação da implementação das estratégias anteriores.

As relativas incoerências do processo de planeamento como instrumento de ordenamento do território eficaz têm sido identificadas e debatidas por vários autores 
sob diferentes perspectivas (sobre a avaliação do interesse público na ocupação e uso do solo ver Needham, 2006). A evidência resultante desta reflexão e da análise de diversos casos de estudo tem demonstrado que as dinâmicas de uso e transformação do solo são relativamente autónomas na resposta a dinâmicas locais e de mercado, não sendo consentâneas, por um lado, com visões positivistas do planeamento associadas a padrões de zonamento rígidos e, por outro lado, com a diversidade de agendas dos diferentes níveis e tutelas da administração pública. (ver, por exemplo, Portas et al, 2003 e 2011; Cabral e Crespo, 2010). Neste artigo pretende-se apenas apresentar um exemplo concreto de um domínio - o zonamento e a programação de áreas para actividades empresariais - que não tem a montante uma prática consistente de avaliações e um acervo suficiente de estudos de caso.

Luís B. Soares (2004, pp. 96), reconhece que a "generalização dos PDM veio reforçar as competências e a 'autonomia' da gestão autárquica no respeitante ao ordenamento do território municipal, mas, ao mesmo tempo" instalar "uma visão fragmentada e localista dos problemas territoriais e da sua resolução", e considera que tal terá sido acentuado "pela ausência de políticas e de instrumentos de ordenamento do território de escala supramunicipal". Ou seja, teriam faltado "políticas de enquadramento" e prevalecido "a total incapacidade de produzir instrumentos de coordenação e integração territorial dos planos municipais" (Soares, 2004, pp. 96). Porém, como se tentará demonstrar, a "intervenção descoordenada, casuística e sem orientações consistentes" que "teve, muitas vezes, efeitos directos na incoerência e posterior falta de aplicabilidade dos planos" imperou mesmo com o enquadramento de um PROT: o PROT Algarve (1991), anterior a qualquer um dos 16 PDM. Não será, então, apenas um problema de ausência de quadro de referência estratégico, integrador e de escala regional, mas sim um problema com, pelo menos, duas vertentes: i) a clareza e assertividade desse e de posteriores quadros orientadores, para o tema que o presente artigo aborda: as áreas para as actividades empresariais; e ii) uma das "condicionantes de fundo" do "debate sobre a política regional para o país" reside nas "práticas dos distintos actores locais e regionais, e a sua disposição e capacidade para se pensarem colectivamente em função de um projecto territorial comum" (Ferrão, 2004, pp. 74).

A desarticulação e a descoordenação estão presentes em dois momentos: i) na geração inicial de planos supramunicipais e regionais, entre entidades e organismos da administração central e central desconcentrada; ii) na seguinte geração desses planos 
nos quais as entidades da administração local foram chamadas, senão a uma elaboração conjunta, pelo menos à concertação, prevista pela Lei de Bases da Política de Ordenamento do Território e Urbanismo, LBPOTU (Lei n.o 48/98, de 11 de Agosto; e DL n. $\cong$ 380/99, de 22 de Setembro). Assim, não é apenas, numa primeira fase, uma desarticulação entre conceptualizadores e executores (dois níveis distintos), mas também a posterior extensão dessa desarticulação para um quadro de responsabilidades comuns e partilhadas por aqueles dois conjuntos de agentes. $\mathrm{O}$ artigo reporta somente à componente actividades empresariais e à sua territorialização mas, eventuais análises sobre outras actividades do "projecto territorial comum" - turismo, rede urbana e equipamentos, as actividades agrícolas, etc. - apresentariam muito certamente os mesmos resultados.

Houve legítimas expectativas de que, feito o balanço em matéria da avaliação dos PDM e da articulação entre os níveis da administração, suprimidos ou corrigidos os constrangimentos e aspectos críticos, melhoradas as componentes instrumentais (cartografia, recursos humanos, etc.) e, sobretudo, com a nova lógica de abordagem das questões do território veiculadas pela LBPOTU, poderiam vir a ter lugar mudanças no planeamento e gestão das transformações do território. A LBPOTU redefiniu a atribuição de competências e responsabilidades na gestão territorial (pelas escalas central, regional e local), e partiu de um optimismo no qual estavam criadas as condições para a melhor articulação entre as estratégias, a montante, e o exercício do planeamento, a jusante. Estariam assim melhoradas as condições para uma "cultura de reflexividade, concertação estratégica e cooperação de base territorial" (Ferrão, 2004, pp. 74).

A Revisão do PROT (2007) é elaborada neste quadro. Os planos da competência da administração central têm um carácter essencialmente estratégico, cabendo aos municípios, em sede de plano director, definirem a estratégia de desenvolvimento municipal e o modelo de ordenamento territorial. Como se tentará demonstrar, a estratégia veiculada pela Revisão do PROT, em matéria da programação de áreas de acolhimento empresarial é vaga, ainda mais do que o documento estratégico que the esteve subjacente (EDA 2007-2013), para além de que o Observatório criado para a monitorização da implementação do PROT não contempla, como havia sucedido com o PROT 1991, as áreas de acolhimento empresarial. Assim, contrariando o quadro optimista que conferia "maior importância às visões estratégicas e aos processos de formulação, execução, acompanhamento e avaliação das políticas..." (Ferrão, 2004, pp. 
75), no qual as CCDR poderiam não apenas desempenhar um papel como "gestor estratégico do desenvolvimento territorial", mas também "corrigir os erros do passado" e "promover novas formas de relação institucional entre departamentos da administração central e entre estas e as autarquias" (Soares, 2004), verificou-se que, pelo menos no Algarve, a oportunidade não foi aproveitada, e o papel não foi cumprido.

A expressão territorial e, assim, a relativa eficácia das estratégias delineadas e dos instrumentos para a sua operacionalização é visível sob as mais diversas formas. A olho nu, ao percorrer o principal eixo viário da Região - a EN/ER 125 -, torna-se evidente. Por um lado, a imparável ocupação da envolvente daquele eixo por pequenas e médias indústrias, pequeno e grande comércio, oficinas e serviços, quando os IGT definem outros usos para a grande maioria dos terrenos ocupados por aquelas actividades. Por outro lado, estando os PDM em vigor há já 15-20 anos, esperar-se-ia que, sobretudo ao longo do mesmo eixo, houvesse no terreno uma expressão do uso que o plano define, uma transposição para o terreno das suas intenções. No entanto, observam-se ocupações idênticas em ambos os lados do eixo - proliferação de estabelecimentos -, quando o plano define usos distintos para cada um dos lados do eixo. Duas décadas decorridas sobre a vigência dos PDM, seria já tempo de se ter no terreno a correspondente dos usos que constam nas plantas de ordenamento dos planos.

Esta questão orienta a investigação para outro nível de interrogações que o artigo procurará enquadrar. Será que a distribuição de áreas para o acolhimento de actividades empresariais e a sua programação/execução decorre da transposição para os PDM de uma estratégia desadequada? Porque é que os PDM não conseguiram romper com lógicas de localização anteriores - isentas do exercício de planeamento e ordenamento - que privilegiaram as localizações "naturais" definidas por factores como, em regra, a proximidade aos principais eixos e nós viários? Será que os PDM assumiram diagnósticos superficiais, ou errados, e não incorporaram evidências, não previram tendências e não entenderam as lógicas de localização das áreas empresariais? Para tais questões, e para se entender o generalizado insucesso das orientações em matéria de áreas empresariais, as respostas, mesmo que parciais, são afirmativas.

Por esse motivo, são utilizadas expressões como "relativa eficácia" ou "relativo insucesso". Há, porém, exemplos bem-sucedidos de como a estratégia definida no PDM, suportada por uma vontade política forte e por uma eficiente programação e afectação de meios, está a ter resultados e a cumprir os objectivos referidos nas estratégias 
regionais e nos IGT. Identificar-se-ão exemplos e concluir-se-á com um dos objectivos fundamentais da ideia subjacente à plataforma www.algarveacolhe.com: a identificação de bons exemplos de áreas de acolhimento empresarial que se podem constituir como modelos a seguir em sede de revisão dos PDM.

\section{Os espaços para o acolhimento empresarial nos documentos estratégicos e nos IGT}

Ao longo do artigo serão utilizadas expressões com significados semelhantes mas que se reportam a realidades diferentes. Para melhor se compreender o conteúdo e o contexto em que expressões como áreas de acolhimento empresarial (ou área para o acolhimento de actividades empresariais) e espaços para o acolhimento de actividades empresariais são utilizadas, entende-se por conveniente uma prévia clarificação. A primeira reportase a uma concentração de empresas e de actividades (em parcelas ou lotes), e de instalações livres (para venda e ou aluguer). Estas aglomerações de empresas, actividades e superfícies/instalações disponíveis apresentam as mais diferentes formas e géneses e os mais diversos graus de programação, ocupação e de compactação. Entende-se por espaços para o acolhimento de actividades empresariais aqueles que foram inscritos nos planos municipais de ordenamento do território (PMOT) para a circunscrição das áreas de acolhimento empresarial. Estes espaços são bastante heterogéneos, compreendendo um vasto leque de ocupações e de usos. Embora os PDM os tenham circunscrito para fins industriais e empresariais, em alguns casos já existentes à data da sua elaboração e publicação, em muitos deles persistem as ocupações e usos anteriores - habitação, agricultura, etc.

Como se depreende, existem espaços sem áreas e áreas fora de espaços. Neste artigo serão abordadas as dinâmicas ocorridas nos espaços e respectivas áreas, essencialmente porque é para esses espaços que, por imperativos do ordenamento do território, se deverão transpor e materializar as estratégias de desenvolvimento. Serve também esta clarificação para afastar qualquer eventual interpretação daquelas duas terminologias como transposições de uma figura legalmente criada com a designação de Área de Localização Empresarial (ALE), criada e definida pelo DL no 46/2001, de 10 de Fevereiro. Não existe no Algarve nenhuma área enquadrável nesta figura, embora duas áreas, referidas mais adiante, apresentem alguns dos seus aspectos distintivos. 


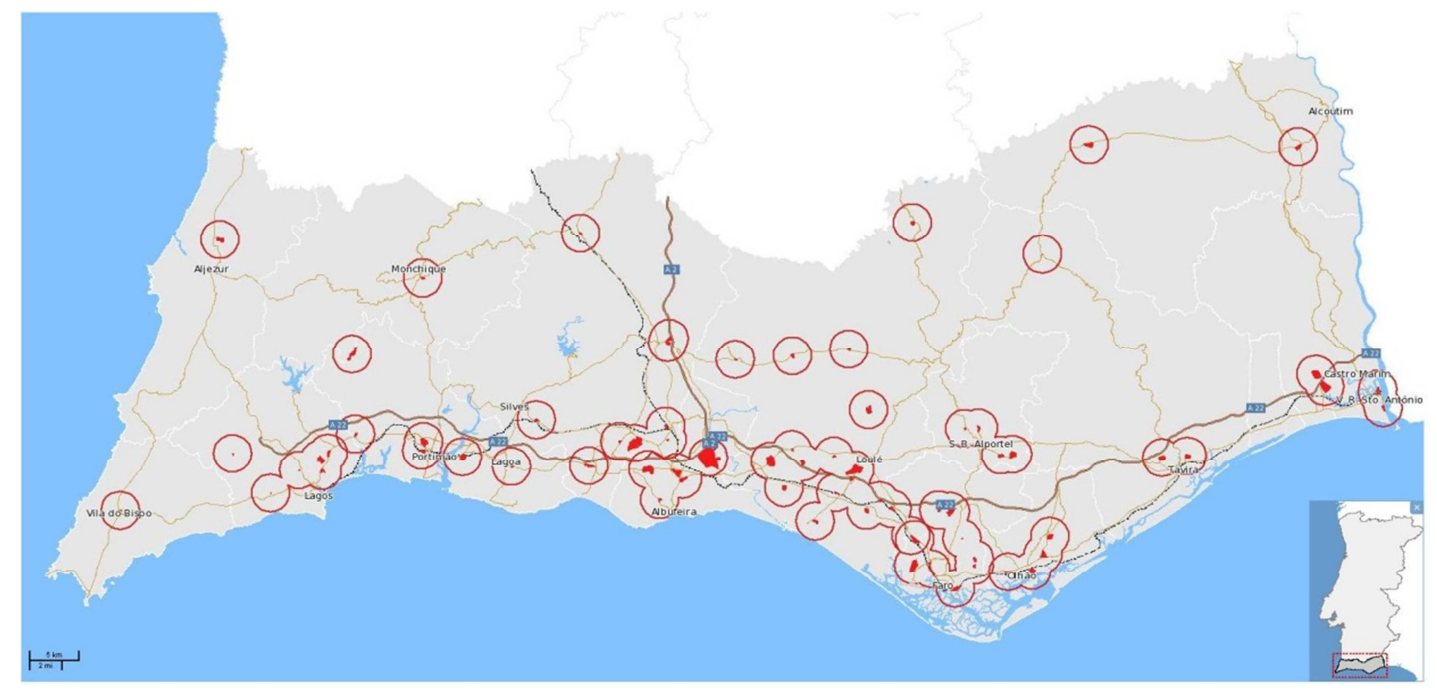

Figura 1 - Espaços definidos nos PMOT para o acolhimento de actividades empresariais (Algarve)

\subsection{O Plano Regional de Ordenamento do Território do Algarve (1991)}

O PROT Algarve (1991) continha muito poucas orientações, e muito genéricas, sobre as áreas de acolhimento empresarial. Para a questão das áreas empresariais limitou-se a identificar "áreas alternativas de concentração industrial" e a sugerir a sua localização na envolvente de 4 aglomerados: Tunes, Faro, Loulé e Castro Marim. O plano sugeria as 4 novas áreas de escala sub-regional (as existentes estariam saturadas?), adiantava parâmetros genéricos (dimensão, distância ao aglomerado mais próximo, etc.), e recomendava o fomento de uma rede de pequenas áreas, de âmbito local.

Este plano revelou-se pouco assertivo quanto a orientações para as áreas de acolhimento empresarial, e delegou a matéria nos PDM. Não teria sido precoce a referência à diversificação do tecido produtivo regional, como posteriores documentos estratégicos a fizeram. À época (1991), as preocupações eram o ordenamento e a contenção da expansão urbana, o esforço de impedir a descaracterização física da Região, a salvaguarda dos atractivos e das potencialidades turísticas e a protecção dos espaços naturais, ameaçados por duas décadas de intensa construção. Por outro lado, este plano não tinha associado um programa de execução que identificasse os domínios de actuação, as acções/projectos a desenvolver, uma estimativa dos montantes financeiros necessários, a definição de prioridades e as fontes de financiamento.

A irrelevância dada pelo PROT 1991 à questão do acolhimento empresarial ficou evidente no Estudo de Avaliação do PROT Algarve 1989/1996 (CEDRU, 2000). 
Reportando-se aos primeiros 5 anos de vigência do PROT, o estudo aborda uma série de domínios - demografia, sistema urbano, infraestruturação do território, etc. - com algum pormenor mas, em matéria de áreas empresariais, a abordagem é muito sumária: constata-se a perda de população activa na indústria; e afirma-se não terem sido “... cartografadas áreas industriais concretas mas apenas concentrações industriais..." (CEDRU, 2000, pp.9). A avaliação aborda a transposição das orientações do PROT para os PDM quanto ao zonamento e criação de áreas de âmbito local/municipal mas, contrariamente a outras dinâmicas abordadas (por amostragem), não se debruça sobre a programação, a emissão de alvarás, a infraestruturação, a instalação de empresas e a ocupação das áreas empresariais. Destaque-se ainda a opinião dos autarcas quanto aos "efeitos gerados pelo PROT Algarve 1991" no domínio "actividade industrial": um autarca não respondeu; onze consideraram os efeitos "nulos"; e os restantes quatro consideraram os efeitos "positivos mas reduzidos" (CEDRU, 2000, pp. 153).

\subsection{As áreas de acolhimento empresarial nos planos directores municipais}

Houve, refere a avaliação, uma concordância dos PDM com as orientações veiculadas no PROT. Não terá sido plena, também porque as orientações eram vagas mas, efectivamente, foram definidas nos PDM as 4 "áreas alternativas". Da mesma forma, foram definidas "as segundas linhas" de "áreas afectas ao uso industrial, de interesse local ou concelhio..." (CCR Algarve, 1990, pp. 48). Contudo, nem as primeiras se afirmaram como o "cordão" de áreas empresariais de âmbito sub-regional, nem as segundas como uma segunda linha de áreas de nível hierárquico inferior. A delimitação destas áreas nos PDM, tendo que ser inclusiva com as pré-existências e acolher outros condicionalismos, produziu um quadro de áreas caracterizado por uma extrema heterogeneidade, tendo no entanto um aspecto bem vincado: a ausência de uma hierarquia de áreas empresariais definida nos níveis sub-regional e local/municipal, como o PROT pretendia. Como resultado, os 16 PDM aprovados após o PROT definiram um total de 64 espaços para acolhimento de actividades empresariais.

Sendo expectável, face às especificidades dos municípios da Região, que existam concelhos com mais espaços que outros, é no entanto óbvio que, na elaboração dos PDM, não houve uma lógica comum a todos os concelhos no que respeita à definição e delimitação de espaços para fins empresariais. Os parâmetros indicados pelo PROT, quanto a dimensões e distância aos centros urbanos, terão sido também interpretados como meramente indicativos. Das 4 "áreas alternativas", apenas duas (Loulé e Castro 
Marim) têm mais de 50 ha (as outras duas têm 13,6 e 8,7 ha). Algumas destas áreas não passaram de intenções uma vez que, ou não tiveram concretização (Tunes e Castro Marim) ou, quando a tiveram, ficou aquém do esperado (S.B. Alportel). A concretização falhou também, no caso destas quatro áreas (que se pretendiam estruturantes), pelos seguintes aspectos: i) na generalidade, os acessos não foram executados; ii) frequentemente, o perímetro definido em PDM não considerou (ou remeteu a questão para um plano de ordem inferior), o cadastro e a existência de outros usos, designadamente o uso habitacional.

Haveria mais aspectos a considerar na avaliação da execução das 4 áreas propostas pelo PROT. No entanto, e passados 20 anos sobre a sua entrada em vigor, a melhor avaliação consistirá, sem dúvida, na actual ocupação destas áreas. Apenas uma destas áreas (Loulé) cumpriu o seu desígnio. As restantes nunca se afirmaram. A área de S.B. Alportel tem 5 estabelecimentos; as de Tunes e Castro Marim nunca se concretizaram.

A delimitação de espaços para as actividades empresariais nos PDM terá assim, com o enquadramento genérico dado pelo PROT, seguido outras lógicas incutidas por cada um dos municípios e das equipas que os elaboraram. Na ausência de uma metodologia de origem, poder-se-á a posteriori estabelecer um conjunto de tipologias de espaços para o acolhimento empresarial que enquadra os 64 espaços definidos nos planos. Assim, os PDM: i) delimitaram áreas onde havia já concentrações de empresas; ii) circunscreveram áreas com loteamentos industriais e comerciais executados antes dos PDM (incluindo, por vezes, terrenos na envolvente para eventuais expansões); iii) circunscreveram grandes unidades industriais que, não constituindo áreas empresariais, não poderiam ter outra classificação no PDM que não a industrial; iv) identificaram áreas, interessantes em termos de proximidade a nós viários, considerando que o conjunto de estabelecimentos existente (nalguns casos, muito reduzido) fosse capaz de atrair outros estabelecimentos; $v$ ) identificaram áreas onde, não havendo pré-existências de natureza empresarial, se considerou, atendendo à proximidade de nós/eixos viários, ou de lugares com dimensão, que deveria existir um espaço para fins empresariais.

\subsection{As áreas de acolhimento empresarial definidas em planos de pormenor}

Os PDM, nos artigos que dispõem sobre as "áreas industriais, comerciais e de serviços", são claros quanto à obrigatoriedade de os espaços serem objecto de Planos de Pormenor (PP) ou operações de loteamento. Em rigor, apenas em 1 dos 64 espaços previstos nos PDM houve lugar à elaboração, aprovação e publicação de um plano de 
pormenor (PP da Área Industrial de Santa Margarida - Tavira, RCM n 24/2003, de 19 de Fevereiro). As restantes programações foram por via dos loteamentos. Porém, apenas em 24 dos 64 espaços definidos em PDM para fins empresariais tiveram lugar operações de loteamento aprovadas e executadas posteriormente à data de entrada em vigor dos planos, sendo que daqueles, 5 tinham já loteamentos anteriores à entrada em vigor dos planos. Para além daqueles 24 espaços, há ainda outros 7 com operações de loteamento concretizadas antes da entrada em vigor dos planos. Constata-se, assim, a fraca programação dos espaços previstos nos PDM, uma vez que, mesmo contabilizando os que tinham já loteamentos concretizados, em apenas 31 dos espaços previstos em plano ( $48 \%$ do total) - somente $23 \%$ do total da superfície prevista no conjunto dos PDM teve lugar a programação para fins empresariais. Nos restantes 33 espaços (e $77 \%$ da superfície) a ocupação permanece, grosso modo, idêntica à que existia antes dos PDM.

A consciencialização, por alguns executivos camarários, de que o "exercício de planeamento" subjacente ao padrão de localização e a estratégia de programação de espaços para as actividades empresariais expressos nos PDM não estaria a resultar, terá sido a razão para, muitos anos após a entrada em vigor dos planos, terem sido publicados 9 PP - Portimão, Tavira, Faro, Lagos (3), Loulé (2) e Castro Marim - que contemplam, total ou parcialmente, lotes para acolher empresas. Todos estes PP significaram alterações dos PDM, em terrenos afectos a outros usos e condicionantes, e levam à conclusão de que, pelo menos nestes municípios, houve o entendimento que, não forçosamente o número de espaços previstos, mas sobretudo as suas localizações e os mecanismos para a programação destas áreas, não seriam os mais adequados. Este "reforço" de novos espaços é passível de várias interpretações: i) muitos dos definidos em PDM não se revelaram interessantes para a iniciativa municipal (e privada); ii) mesmo nos espaços com vocação para as actividades empresariais, a iniciativa privada foi insuficiente para a constituição de uma oferta de terrenos e de instalações, pelo que os municípios chamaram a si a iniciativa de definir e programar estas áreas.

Note-se também que estes 9 planos são muito posteriores à entrada em vigor dos PDM (entre 10 e 16 anos). Considerando que a vigência destes últimos é de 10 anos, seria este o tempo em que os municípios estariam, não a publicar PP que alteram os usos definidos nos PDM, mas sim a concluir os respectivos processos de revisão, a apresentar a redefinição da estratégia para as actividades empresariais e a transpô-la para o zonamento. Ao invés, os PP vêm coexistir com os espaços definidos nos PDM; não vieram desenvolver e concretizar as estratégias e propostas do plano director mas, sem 
as rever, adaptar ou (mesmo) suprimir, resultam num averbamento de "novas orientações" - não articuladas e repensadas num quadro mais vasto de âmbito regional ou municipal - para o desenvolvimento das actividades empresariais. Não houve uma revisão da estratégia para as actividades empresariais, mas sim a sobreposição (ou justaposição) da anterior, e do seu zonamento, com intenções isoladas.

As evidências sustentam estas conclusões. Alguns dos municípios (Loulé, Portimão) que publicaram PP são municípios onde a oferta de lotes e de instalações é largamente excedentária. Em Castro Marim, onde em 10 anos não se fixou uma empresa no espaço definido em plano, sem se demonstrar real ou potencial capacidade de captação de empresas, publicou-se um PP em cuja área se poderia concentrar $1 / 3$ de todos os estabelecimentos instalados no conjunto de todos os 73 espaços da Região. Destaque-se que, destes 9 planos, apenas um foi concretizado (Portimão), embora nenhuma empresa ainda se tenha fixado. Os restantes oito planos não tiveram concretização. Para completar esta breve retrospectiva sobre as dinâmicas dos espaços definidos nos PDM para as actividades empresariais, julga-se pertinente, porque corrobora a falta de dinamismo apontada, referir a absoluta inexistência de aprovações, em matéria de áreas empresariais, em sede do Programa Operacional Regional (QCA II, 1994-2001) - ou seja, nos primeiros 6-7 anos de vigência dos planos directores -, e a uma procura igualmente muito baixa ${ }^{1}$ no quadro comunitário seguinte (PO Regional, QCA III, 2000-2006).

\subsection{As áreas de acolhimento empresarial na "Estratégia de} Desenvolvimento do Algarve" (2007-2013) e na Revisão do PROT Algarve, de 2007

O falhanço, nesta matéria, foi assumido no diagnóstico da Estratégia de Desenvolvimento do Algarve 2007-2013 (CCDR Algarve, 2006). A análise refere que “... apesar da relativa concentração espacial das empresas industriais há, em contrapartida, uma significativa dispersão de zonas industriais na região, ... (...). Esta dispersão contrasta igualmente com a ausência de áreas de localização industrial, em termos específicos, e de localização, em termos gerais" (CCDR Algarve, 2006, pp. 24).

\footnotetext{
1 Apenas foram financiados 3 projectos/acções de "zonas empresariais locais": Feiteirinha (Aljezur), Loteamento Municipal das Quatro Estradas (Alcoutim) e Área Empresarial de Tavira -, que totalizaram uma comparticipação de 5,19 M €.
} 
Inequivocamente, o documento reconhece a ineficácia das anteriores estratégias e planos. É referida "... uma ausência de planificação para a implantação industrial nos aglomerados e zonas industriais. Não existe qualquer levantamento sistematizado da tipologia de empresas localizadas nessas áreas nem uma estratégia específica para o sector que permita seleccionar as indústrias a atrair para aqueles espaços" (CCDR Algarve, 2006, pp. 24). As orientações propostas pelo PROT não colheram e a aplicação e gestão dos PDM descurou a planificação das "zonas industriais". O estudo refere ainda: "a persistência de um absoluto desconhecimento da ocupação das áreas de acolhimento"; e, "concomitantemente, a ausência de uma estratégia que permita definir as actividades que deverão ser captadas e fixadas naquelas áreas." Registe-se que estes aspectos ficaram amplamente comprovados nos levantamentos efectuados no quadro do projecto www.algarveacolhe.com. Em muitos espaços definidos em PDM, mesmo em loteamentos municipais, muitos dos estabelecimentos não são das actividades que se pretenderia inicialmente acolher.

Para além de apontar a indefinição/difusão do padrão locativo das áreas empresariais, o documento critica a ausência de uma estratégia de atraç̧ão de empresas, a não definição de um perfil das empresas a atrair, e ainda a inexistência de "entidades gestoras" que consigam fazer descolar as áreas existentes de meros loteamentos "onde foram instaladas as infraestruturas base convencionais" sem uma "gestão condominial". Actualmente, vários anos passados sobre o diagnóstico (de 2006), parte significativa dos municípios não tem qualquer loteamento ou área de iniciativa municipal afecta a estes usos e, outros, nem tão pouco de iniciativa privada. Com excepções, os loteamentos municipais são áreas que os municípios urbanizaram e alienaram a preços baixos, permitindo que os proprietários dos lotes os mantenham expectantes. Não está prevista a reversibilidade dos lotes e, quando há de facto a instalação de um estabelecimento, não há critério de selecção (para além das restrições de natureza ambiental).

Desta forma, os municípios abdicaram da capacidade de implementar uma estratégia de captação e fixação de empresas e de definir um rumo para o sector produtivo do município. Não deixa de ser notório, designadamente pela discordância que, após a delegação nos municípios de competências nos domínios do ordenamento do território e do licenciamento de actividades (que os municípios vinham reclamando), uma boa parte dos municípios receba as competências e não as exerça, como instrumentos que são, para o crescimento económico e o desenvolvimento dos seus concelhos, precisamente os argumentos levantados na reclamação das competências. 
A EDA 2007-2013 refere a necessidade de “... uma nova estratégia de atracção de empresas de nova geração, ... conjugar a disponibilidade de infra-estruturas avançadas, acessibilidades de qualidade, serviços qualificados de apoio...", enfatiza a necessária "organização planeada do espaço" e propõe "assegurar a criação de uma rede de áreas empresariais...". As prioridades e linhas de actuação para operacionalizar tais intenções referem a "promoção de zonas de localização empresarial consolidadas que assegurem o ordenamento das actividades económicas e da logística regional" e a definição de "um modelo de localização de Zonas Industriais de Nova Geração para a implementação de empresas com forte conteúdo tecnológico" (CCDR Algarve, 2006, pp. 25).

O documento contém ainda, para além do diagnóstico crítico sobre a actuação das entidades públicas e do sector privado, uma nova terminologia. Deixou de haver referência às "áreas industriais" e são melhor especificados os "formatos" de aglomeração das actividades produtivas: a assunção da logística como um vasto conjunto de actividades que envolve, a montante e a jusante, a tradicional transformação e que, assim, importa beneficiar das sinergias propiciadas pela aglomeração; o destaque para a necessidade de criar áreas para empresas e serviços intensivos em conhecimento - os "centros/pólos de transferência tecnológica".

As propostas constantes na EDA 2007-2013 viriam a ser transpostas para a Revisão do PROT Algarve (RCM n.o 102/2007, de 3 de Agosto); quer porque a entidade responsável pela elaboração de ambos é a mesma - CCDR Algarve - quer porque os consultores nestes domínios foram, também, os mesmos. Todavia, e tendo a figura do PROT, por força das alterações introduzidas na LBPOTU, adquirido um carácter orientador e estratégico, serão os PMOT a efectuar a "tradução" destes princípios e normativas.

Na Revisão do PROT Algarve, dificilmente se vislumbrariam as áreas para o acolhimento empresarial se o documento, por entre parques temáticos, museus, teatros, hospitais, centros de congressos, etc., não identificasse os equipamentos de âmbito regional "estruturantes para o sistema territorial do Algarve...". De entre uma listagem numerosa, sobressaem: um "Tecnopólis Portimão-Lagos - 2 centros especializados na criação de actividades inovadoras e sistemas inteligentes"; um "Pólo Tecnológico da Universidade do Algarve, no Parque das Cidades"; um "Parque das Novas Actividades Aglomeração Faro-Loulé-Olhão, incluindo o Pólo Tecnológico do Algarve"; e mais 3 parques, obviamente tecnológicos, em outras tantas localizações, de sectores como a cortiça, as ciências do mar e a energia solar (CCDR Algarve, pp. 47). 
O acolhimento empresarial é também abordado no ponto "1.7 Estruturação das Redes de Transporte e Logística", nomeadamente nos Objectivos Operativos para a Rede Logística, onde é referida a concretização do "sistema regional de logística e áreas de localização empresarial apoiado" em 4 centros de âmbito regional - "Centro Empresarial e de Logística de Tunes"; "Área de Negócios do Sotavento Algarvio"; "Mercado Abastecedor da Região de Faro (MARF) " e "Área Empresarial do Barlavento" - e a conclusão e consolidação da "rede de parques empresariais municipais". Em suma, a Revisão do PROT Algarve 2007 consegue ser, ainda, mais genérica do que a EDA.

Não pretendendo a confrontação exaustiva sobre o que dispõem o PROT 1991 e a sua Revisão para as áreas empresariais, há no entanto importantes semelhanças e dissemelhanças a destacar, a saber: i) a Revisão de 2007 enuncia 6 pólos tecnológicos, transpondo assim para o território mais uma terminologia do que propriamente projectos concretos; ii) a manutenção de uma perspectiva de hierarquização das áreas empresariais - 4 centros de âmbito regional e uma rede de áreas municipais; iii) a assunção, mais clara em 2007, de que as áreas do sistema regional deverão posicionarse no corredor do principal eixo viário - a A22 -, atribuindo-se assim às actividades logísticas o ambiente "enquadrador" das áreas de localização empresarial; iv) a Revisão do PROT deixa de referir as áreas para Loulé e São Brás de Alportel; v) a Revisão do PROT confirma uma área consolidada e em funcionamento - o MARF -; "repesca" no PROT 1991 duas áreas que não tiveram concretização - Tunes e Castro Marim -; e "lança" uma nova área - Área Empresarial do Barlavento -, sem antecedentes e sem posteriores desenvolvimentos. Houve porém, na Revisão do PROT, a preocupação de associar ao documento um Programa de Execução, embora meramente indicativo.

\section{Situação actual dos espaços dos PMOT para fins}

\section{empresariais}

Em resultado dos processos de definição, programação e ocupação dos espaços para actividades empresariais, o cenário actual, em termos de número, distribuição, génese, e forma/tipologia (espontânea ou programada) das áreas empresariais é muito heterogéneo. Após a apresentação, nos pontos anteriores, numa sequência cronológica necessariamente muito sintetizada, da constituição e génese dos espaços para o acolhimento de actividades empresariais no Algarve, faz-se a seguir um resumo da situação actual destes espaços, assim como das figuras pelas quais se constituíram. 
Os PMOT (PDM e sequentes PP) previram um total de 73 espaços para o acolhimento de actividades empresariais. É, sem dúvida, um número excessivo. Tal significa que está previsto em PMOT um espaço para o acolhimento de actividades empresariais em cada $68,5 \mathrm{~km}^{2}$; ou seja, distando em média do espaço mais próximo não mais do que $8,3 \mathrm{~km}$. Destes 73 espaços, somente 43 tiveram programação (PP ou loteamento), sendo que apenas houve execução em 35 destes 43; ou seja, e em relação ao total (73 espaços em PMOT), apenas houve, em quase duas décadas de PDM, execução em $48 \%$ dos espaços. Porém, a taxa de ocupação dos lotes é baixa. Uma parte bastante significativa dos 1.585 lotes executados, não tem edificação e está livre (22\% do total); e uma outra parte também significativa das naves edificadas nos lotes $(13,3 \%)$ está para venda ou aluguer, sendo que uma parte importante destas naves nunca teve ocupação. Por outras palavras, somente $52 \%$ dos lotes tem empresas a laborar.

Quanto a empresas instaladas nos espaços definidos nos IGT, o seu número é de 885 (empresas e estabelecimentos). Mais relevante que o número destas empresas, sem dúvida baixo, é a sua estrutura: i) apenas 167 das empresas (18,9\%) estão classificadas nas actividades industriais; ii) apenas 38 (4,3\%) estão nas actividades afectas à logística e transportes; iii) e apenas 181 (20,4\%) estão classificadas como comércio grossista. Os serviços às empresas são em número residual e as empresas classificadas em sectores como o comércio retalhista e stands e oficinas auto têm um peso excessivo (32\%). Em número significativo, e crescente, estão as empresas de serviços pessoais e domésticos, clubes e associações recreativas e culturais, incluindo equipamentos na área da saúde e até escolares. Como resultado, mais de metade das empresas instaladas não parece ter enquadramento nas classes de espaço tal como estão definidas nos PDM.

O grande número de espaços e de tipologias resultam da coexistência no território: i) das anteriores concentrações de empresas (industriais, comerciais e outras) ou grandes unidades fabris isoladas que os PDM; ii) das áreas que, com os PDM, foram executadas, esmagadoramente por via de loteamentos e só muito excepcionalmente por PP; e iii) das áreas que, antes da revisão dos PDM, foram programadas em sede de PP (apenas uma foi executada, e não tem ainda qualquer ocupação).

Em matéria de "espontaneidade" das áreas empresariais, reconhece-se a acção positiva dos IGT: desde o PROT 1991 e a entrada em vigor dos PDM, não surgiram mais concentrações de empresas em regime de licenciamento individual. Ou seja, procedendo à circunscrição das antigas áreas ocupadas pelas unidades transformadoras tradicionais - não significando contudo que tenha havido uma estruturação ou requalificação destas áreas de forma a melhorar as condições de laboração - a entrada 
em vigor dos PDM terá, pelo menos, impedido novas concentrações "espontâneas". Pontualmente, instalaram-se unidades, armazéns e superfícies (grossistas ou retalhistas) sem enquadramento a montante mas, regra geral, começou a prevalecer a figura do loteamento. Porém, sendo esta a realidade nos espaços previstos para a instalação de actividades empresariais nos PDM, o mesmo não ocorreu fora deles. Sobretudo na envolvente dos grandes eixos, persiste a instalação de estabelecimentos e de actividades que, pela sua natureza, deviam estar nas áreas para tal previstas nos PDM.

Com os PDM vingou a figura do loteamento. De um total de 49 loteamentos para fins empresariais, 36 (73\% do total) foram na vigência dos PDM; embora apenas 73,6\% da área destes 36 loteamentos esteja concretizada. Por outro lado, a grande maioria destes loteamentos (31 em 36) são de particulares. Isto é, com os PDM, os municípios praticamente abdicaram da figura do loteamento municipal, por via dos quais poderiam concretizar a estratégia de captação e fixação de empresas (mecanismos de redução fiscal, baixo custo dos terrenos, etc.) com relação com a base produtiva local e geradoras de cadeias de valor. Dos 11 loteamentos municipais existentes na Região, apenas 5 são posteriores aos PDM. Tem, assim, prevalecido uma generalizada ausência da iniciativa municipal para a dotação dos territórios com as infraestruturas e as condições para procederem à relocalização de estabelecimentos disseminados e atraírem empresas. A situação afigura-se eventualmente mais preocupante quando se verifica que, dos 16 municípios, 5 não têm qualquer loteamento para estes fins.

Como forma de sintetizar, não propriamente numa classificação dos espaços para actividades empresariais segundo as intenções e objectivos dos documentos estratégicos e dos PMOT, mas mais numa "arrumação" segundo a forma como os espaços se afirmaram (ou não) no território - i.e., relacionando as intenções em plano com a dinâmica efectiva desses espaços -, apresenta-se uma "tipologia" dos mesmos segundo as duas referidas vertentes (Quadro 1). A informação apresentada consubstancia a análise e os comentários produzidos, que convergem na constatação da inconsequência e da ineficácia das estratégias veiculadas pelos documentos estratégicos e pelo PROT no que respeita à questão das áreas empresariais.

A inconsequência e a ineficácia podem ser observadas em duas fases: $a$ ) entre 1992 e 1997, com a publicação dos PDM; b) com os PP, após 1997. As duas complementam-se, sendo porém evidente que é uma ineficácia "anunciada". A implementação das áreas empresariais estava à partida fortemente cerceada por um insuficiente diagnóstico regional que, assim, pouco adiantou na definição de uma estratégia, clara e operativa, para a criação daquelas áreas. Como exemplos, e como atrás se referiu, nem o PROT 
1991 apresentava um programa de execução, nem o posterior Estudo de Avaliação do PROT (1989/96) procurou avaliar a implementação das orientações emanadas.

Quadro 1 - Espaços para actividades empresariais previstos nos PMOT: quantitativos da sua programação, execução e ocupação (Algarve, 1992/2011)

\begin{tabular}{|c|c|c|c|c|c|c|c|c|c|c|}
\hline \multirow[t]{2}{*}{ “Tipologia" de espaço } & $\begin{array}{c}\text { Área } \\
\text { Total }\left(^{1}\right)\end{array}$ & \multicolumn{2}{|c|}{$\begin{array}{c}\text { Área } \\
\text { Ocupada * }\end{array}$} & \multicolumn{2}{|c|}{ Total } & \multicolumn{2}{|c|}{$\underset{* *}{\text { Área executada }}$} & \multicolumn{2}{|c|}{$\begin{array}{c}\text { Área } \mathrm{n} / \\
\text { programada } * * *\end{array}$} & \multirow{2}{*}{$\begin{array}{l}\text { Estab. } \\
\% \text { do total }\end{array}$} \\
\hline & $\begin{array}{l}\text { (ha) } \\
\% \text { do } \\
\text { total }\end{array}$ & $\begin{array}{l}\text { (ha) } \\
\% \text { do } \\
\text { total }\end{array}$ & $\%$ & $\begin{array}{l}\text { (ha) } \\
\% \text { do } \\
\text { total }\end{array}$ & $\%$ & $\begin{array}{l}\text { (ha) } \\
\% \text { do } \\
\text { total }\end{array}$ & $\%$ & $\begin{array}{l}\text { (ha) } \\
\% \text { do } \\
\text { total }\end{array}$ & $\%$ & \\
\hline $\begin{array}{l}\text { A - Espaços previstos nos PDM, aprovados no } \\
\text { período compreendido entre } 1992 \text { e } 1997 \text { (64) }\end{array}$ & $\begin{array}{c}1156,8 \\
85,9\end{array}$ & $\begin{array}{c}559,8 \\
86,8 \\
\end{array}$ & 48,4 & $\begin{array}{c}563,3 \\
84,6 \\
\end{array}$ & 48,7 & $\begin{array}{l}33,8 \\
78,7 \\
\end{array}$ & 6,0 & $\begin{array}{l}505,9 \\
100,0 \\
\end{array}$ & 89,8 & $\begin{array}{l}885 \\
99,7\end{array}$ \\
\hline $\begin{array}{l}\text { A.1 - Espaços programados (PP), } \\
\text { concessionados, outros }\end{array}$ & $\begin{array}{c}69,8 \\
5,2\end{array}$ & $\begin{array}{c}45,6 \\
7,1\end{array}$ & 65,3 & $\begin{array}{l}19,5 \\
2,9\end{array}$ & 27,9 & $\begin{array}{c}7,3 \\
16,9\end{array}$ & 37,3 & $\begin{array}{l}12,2 \\
2,4\end{array}$ & 62,7 & $\begin{array}{l}27 \\
3,0\end{array}$ \\
\hline A.2 - Espaços c/ operações de loteamento & $\begin{array}{r}689,7 \\
\mathbf{5 1 , 2}\end{array}$ & $\begin{array}{c}360,2 \\
55,8\end{array}$ & 52,2 & $\begin{array}{c}300,5 \\
45,1\end{array}$ & 43,6 & $\begin{array}{l}26,5 \\
61,8\end{array}$ & 8,8 & $\begin{array}{c}251,1 \\
49,6\end{array}$ & 83,6 & $\begin{array}{l}758 \\
85,4\end{array}$ \\
\hline $\begin{array}{l}\text { A.2.1 - Espaços c/ todas as operações de } \\
\text { loteamento anteriores ao PDM }\end{array}$ & $\begin{array}{r}90,5 \\
6,7\end{array}$ & $\begin{array}{l}70,6 \\
10,9\end{array}$ & 78,0 & $\begin{array}{l}6,6 \\
1,0\end{array}$ & 7,3 & $\begin{array}{l}3,8 \\
9,0\end{array}$ & 58,1 & $\begin{array}{l}2,8 \\
0,5\end{array}$ & 41,9 & $\begin{array}{r}163 \\
18,3\end{array}$ \\
\hline $\begin{array}{l}\text { A.2.2 - Espaços com todas as operações de } \\
\text { loteamento posteriores ao PDM }\end{array}$ & $\begin{array}{r}418,7 \\
31,1\end{array}$ & $\begin{array}{r}172,3 \\
26,7\end{array}$ & 41,2 & $\begin{array}{r}234,2 \\
35,2\end{array}$ & 55,9 & $\begin{array}{l}11,2 \\
26,1\end{array}$ & 4,8 & $\begin{array}{r}201,7 \\
39,9\end{array}$ & 86,1 & $\begin{array}{r}286 \\
32,2\end{array}$ \\
\hline $\begin{array}{l}\text { A.2.3 - Espaços com as operações de loteamento } \\
\text { executadas antes e depois do PDM }\end{array}$ & $\begin{array}{r}180,4 \\
13,4\end{array}$ & $\begin{array}{r}117,3 \\
18,2\end{array}$ & 65,0 & $\begin{array}{r}59,6 \\
9,0\end{array}$ & 33,0 & $\begin{array}{l}11,5 \\
26,8\end{array}$ & 19,3 & $\begin{array}{r}46,7 \\
9,2\end{array}$ & 78,3 & $\begin{array}{r}309 \\
34,8\end{array}$ \\
\hline $\begin{array}{l}\text { A.3 - Espaços criados p/ circunscrever } \\
\text { unidades fabris que já existiam à data de } \\
\text { entrada em vigor dos PDM }\end{array}$ & $\begin{array}{c}108,4 \\
8,0\end{array}$ & $\begin{array}{c}104,7 \\
16,2\end{array}$ & 96,6 & $\begin{array}{l}3,6 \\
0,5\end{array}$ & 3,4 & $\begin{array}{l}0,0 \\
0,0\end{array}$ & 0,0 & $\begin{array}{l}3,6 \\
0,7\end{array}$ & 100,0 & $\begin{array}{l}38 \\
4,3\end{array}$ \\
\hline $\begin{array}{l}\text { A.4 - Espaços definidos em PDM para, } \\
\text { integrando pré-existências, criar } \\
\text { estruturas e fixar empresas }\end{array}$ & $\begin{array}{c}171,9 \\
12,8\end{array}$ & $\begin{array}{c}48,4 \\
7,5\end{array}$ & 28,2 & $\begin{array}{l}123,5 \\
18,6\end{array}$ & 71,8 & $\begin{array}{l}0,0 \\
0,0\end{array}$ & 0,0 & $\begin{array}{c}122,8 \\
24,3\end{array}$ & 99,4 & $\begin{array}{l}59 \\
6,6\end{array}$ \\
\hline $\begin{array}{l}\text { A.5 - Áreas s/ qualquer edificação, s/ uso ou c/ } \\
\text { uso agrícola. A ocupação é a mesma que } \\
\text { existia à data do PDM }\end{array}$ & $\begin{array}{c}117,0 \\
8,7\end{array}$ & $\begin{array}{l}0,9 \\
0,1\end{array}$ & 8,1 & $\begin{array}{r}116,1 \\
17,4\end{array}$ & 99,3 & $\begin{array}{l}0,0 \\
0,0\end{array}$ & 0,0 & $\begin{array}{c}116,1 \\
23,0\end{array}$ & 100,0 & $\begin{array}{c}0 \\
0,0\end{array}$ \\
\hline $\begin{array}{l}\text { B - Aprovados posteriormente à data da entrada } \\
\text { em vigor dos PDM, por via de PP }\end{array}$ & $\begin{array}{c}190,5 \\
14,1\end{array}$ & $\begin{array}{c}85,3\left(^{2}\right) \\
13,2 \\
\end{array}$ & $\begin{array}{c}44,8 \\
\left({ }^{2}\right)\end{array}$ & $\begin{array}{r}102,3 \\
15,4\end{array}$ & 53,7 & $\begin{array}{c}9,1 \\
21,3\end{array}$ & 8,9 & $\begin{array}{l}0,0 \\
0,0\end{array}$ & 0,0 & $\begin{array}{c}3 \\
0,3\end{array}$ \\
\hline $\begin{array}{l}\text { B.1 - PP em vigor, publicados em data } \\
\text { posterior ao PDM, não executados }\end{array}$ & $\begin{array}{c}168,0 \\
12,5\end{array}$ & $\begin{array}{c}72,8\left(^{2}\right) \\
11,3\end{array}$ & $\begin{array}{c}43,3 \\
\left({ }^{2}\right)\end{array}$ & $\begin{array}{l}93,1 \\
14,0\end{array}$ & 55,4 & $\begin{array}{l}0,0 \\
0,0\end{array}$ & 0,0 & $\begin{array}{l}0,0 \\
0,0\end{array}$ & 0,0 & $\begin{array}{c}3\left({ }^{3}\right) \\
0,3\end{array}$ \\
\hline B.2 - PP posteriores ao PDM, executados & $\begin{array}{c}22,4 \\
1,7\end{array}$ & $\begin{array}{c}12,5 \\
1,9\end{array}$ & 55,9 & $\begin{array}{l}9,1 \\
1,4\end{array}$ & 40,7 & $\begin{array}{c}9,1 \\
21,3\end{array}$ & 100,0 & $\begin{array}{l}0,0 \\
0,0\end{array}$ & 0,0 & $\begin{array}{c}0 \\
0,0\end{array}$ \\
\hline $\begin{array}{l}\text { TOTAIS } \\
(73)\end{array}$ & 1347,2 & 645,1 & 47,9 & 665,5 & 49,4 & 42,9 & 6,4 & 505,9 & 76,0 & 888 \\
\hline
\end{tabular}

$\left({ }^{1}\right)$ - A soma das áreas ocupadas e livres não perfaz o total, uma vez que não foram neste quadro incluídas as áreas comprometidas.

$\left({ }^{2}\right)$ - Estes valores reportam-se às áreas previstas nos planos para infraestruturas, acessos, arruamentos, passeios e outros usos (p.e., habitação) incluídos nas áreas dos planos, e não propriamente a uma ocupação efectiva.

$\left({ }^{3}\right)$ - Estes três estabelecimentos estão a laborar na área do plano, que prevê a sua integração em três lotes a executar.

* - A área ocupada reporta-se à área ocupada por estabelecimentos, por outros usos (habitação, etc.), e ainda por infraestruturas.

** _ $\quad$ A área executada reporta-se à área que foi loteada, urbanizada e infraestruturada, actualmente disponível para a edificação.

*** _ _ A área não programada corresponde a toda a superfície livre, sem edificações (mas com outros usos), que não foi objecto de programação (plano de pormenor, loteamento ou outra).

Fonte: CCDR Algarve, 2011

Com orientações pouco assertivas para as actividades empresariais e o seu zonamento, o PROT 1991 deixou a questão entregue ao voluntarismo dos municípios. A esmagadora 
maioria destes procurou acima de tudo "garantir" a expansão dos perímetros urbanos para fins turísticos e residenciais. Como a questão não se conforma com uma abordagem de escala local/municipal, a ausência de um quadro conceptual regional foi negativamente decisiva. A ineficácia é bem visível nos valores apresentados no Quadro 1: i) $48,7 \%$ da superfície dos espaços previstos nos PDM para as áreas empresariais encontram-se desocupados, entregues a outros usos ou mesmo sem uso; ii) $89,8 \%$ desta superfície não teve qualquer programação, e apenas $6 \%$ foi concretizada; iii) $71,8 \%$ da superfície contida nos espaços definidos nos PDM com a intenção de, integrando préexistências, criar estruturas para a fixação de empresas, está livre; iv) 99,3\% da superfície contida nas áreas sem ocupação de natureza empresarial (ou habitacional), sem uso ou com uso agrícola - ocupação que ocorria à data de entrada em vigor do PDM -, encontra-se livre; e $v$ ) até mesmo $55,9 \%$ da superfície dos espaços com todos os loteamentos executados após a entrada em vigor dos PDM se encontra livre, sendo que $86,1 \%$ desta superfície (234,2 ha) não tem programação (PP ou loteamento).

Os posteriores PP - sem trazerem alterações que traduzam um reequacionar da estratégia anterior, e sem que se assumam como um exercício de "relocalização" de áreas previstas em plano, constituindo-se sim como "adições" aos espaços já previstos -, padecem da mesma ineficácia, apenas: i) 1 dos 9 planos foi executado; ii) 8,9\% da superfície dos lotes destes planos foi executada; iii) estão implantados 3 estabelecimentos (que já existiam antes do plano).

A observação do Quadro 1 permite ainda orientar a análise para uma outra realidade. Tendo concluído que os documentos estratégicos elaboraram, em vários momentos, diagnósticos insuficientes, propostas genéricas sem enquadramento e prioridades, e que as "interpretações" ou "transposições" feitas pelos PDM (e posteriores PP) destas estratégias não contribuíram (como o reconhecem os diagnósticos de sucessivos documentos estratégicos) para a criação e consolidação de áreas empresariais na Região, qual será então o padrão de localização e de distribuição destes espaços?

O reduzido número de estabelecimentos nos espaços previstos nos PDM, quando comparados com os totais regionais, e a persistência nestes espaços de muita superfície livre, apesar de a vigência dos PDM ter mais de década e meia, não significa necessariamente que tenha havido uma quebra de dinamismo na instalação de estabelecimentos. De acordo com os Anuários Estatísticos da Região do Algarve (INE), em 1992 havia 1.529 empresas classificadas nas Indústrias Transformadoras com sede na Região (logo, apenas uma fracção do total), apenas 75\% das empresas desta secção 
existentes em 2009. O que ocorreu terá sido a instalação de empresas em terrenos fora dos espaços para tal previstos nos PDM, dando assim de certa forma uma continuidade aos processos de localização e de distribuição espacial das actividades e dos estabelecimentos que existiam antes da entrada em vigor dos PDM.

Esta tese assenta em dois aspectos: o primeiro, pela observação das dinâmicas que contribuíram para um padrão disperso da distribuição das actividades empresariais; o segundo, pela observação do grau de concretização e dos níveis de "consolidação" dos espaços previstos em plano. Quanto à dispersão - a ocupação indiscriminada de espaços previstos para outros usos -, podem ser destacados dois padrões. Um primeiro, a dispersão pura, com a ocupação de terrenos sem uma lógica comum para além da possibilidade de aquisição/arrendamento de um terreno em condições financeiras mais vantajosas, da propriedade do terreno quando é o próprio a instalar a empresa/estabelecimento ou da existência de um ou outro factor locativo relevante (nó viário, proximidades de outra empresa da fileira/subsidiária, etc.). Um segundo, um padrão designado por "dispersão orientada", que tem na Região a máxima expressão na ocupação da envolvente do principal eixo viário regional - a EN/ER 125.

\subsection{Dois casos de sucesso}

A análise elaborada permite afirmar, de forma mais sustentada, que a eficácia das estratégias, do planeamento, do zonamento e da gestão dos espaços e das áreas para acolher as actividades empresariais têm sido extremamente reduzidas. Contudo, há casos que deveriam ser seguidos e adaptados. Estes casos enfrentam dificuldades várias: a secundarização num quadro regional que sempre privilegiou outras actividades (construção, imobiliária, turismo); o débil tecido produtivo da região, consequência da desestruturação das actividades económicas não directamente relacionadas com as citadas actividades; a ausência de volume e de massa crítica do mercado regional; o carácter periférico da Região, no domínio da produção, mas também em matéria de inserção nas grandes redes de transporte e de comunicações; e, também, a ausência de uma cultura e de uma prática de articulação entre e dentro das próprias entidades e organismos, que permitam orientar as actuações para um desígnio comum e criar os procedimentos para a concretização desses objectivos. Neste contexto, e com os constrangimentos acima apresentados, destacam-se duas iniciativas desenvolvidas na 
Região: 1) o Mercado Abastecedor da Região de Faro (MARF), no concelho de Faro; 2) a Zona Industrial da Feiteirinha, concelho de Aljezur.

O MARF instalou-se num espaço para o qual o PDM de Faro previa a criação de um mercado abastecedor grossista para o sector hortofrutícola regional. Sem perder a sua função original, o MARF diversificou e reorientou a sua actividade para a distribuição e a logística, potenciando a sua localização geográfica. Actualmente, para além do mercado grossista e de empresas do comércio por grosso, estão instaladas 11 das 39 empresas dos "Transportes e Armazenagem" a laborar nas áreas empresariais da Região (28\% do total), unidades da indústria transformadora (com elevado grau de tecnologia) e vários serviços de operadores à escala regional.

A iniciativa desenvolvida em Aljezur, num contexto geograficamente menos favorável, é também notável. Seguindo as orientações do PROT 1991, o Regulamento do PDM definiu a criação da Zona Industrial da Feiteirinha. O enunciado é muito genérico, eventualmente até menos elaborado do que o de outros PDM da Região. Em 1998 é emitido o Alvará de Loteamento para a Zona Industrial, e as infraestruturas são concluídas em 2003. Houve no entanto a percepção de que a dinâmica incutida ao processo não estaria a resultar. Para além da relocalização de algumas oficinas, a procura dos lotes era praticamente inexistente. A prática habitual de concluir as obras de urbanização e esperar por interessados não gerou resultados. Neste contexto, a autarquia constituiu uma estrutura (informal) - o CADE (Centro de Apoio ao Desenvolvimento) - que, desde o início se concentrou no objectivo claro e explícito de funcionar como uma "agência" de captação de empresas e de investimento e, simultaneamente, coordenar internamente todas as fases de tramitação nos serviços camarários de uma intenção de investimento.

A zona industrial não está totalmente ocupada, o que sucede por existir critério na apreciação das pretensões. A prática corrente de alienar lotes para actividades indiferenciadas não é aqui seguida; pelo contrário, privilegiam-se as empresas com domicílio fiscal no concelho, que criem relações com a base produtiva local, que criem novas frentes para os recursos locais, ou que redescubram e desenvolvam actividades/fileiras que projectem o concelho.

Destes dois casos há a destacar sobretudo o seguinte: $i$ ) ambas as áreas têm entidades gestoras, importantes na captação de empresas e na gestão e manutenção das infraestruturas - necessidade fundamental relevada pelos documentos estratégicos - , 0 que não sucede em nenhuma outra área da região; ii) estas entidades gestoras, para 
além do aspecto de gestão condominial tradicional, desenvolvem outras frentes de trabalho como candidaturas a programas de financiamento, apoio à comercialização, assessorias fiscais e jurídicas, etc.; iii) em Aljezur existe um mecanismo de reversibilidade do lote (cujo custo é simbólico), eficientemente aplicado quando o proponente não cumpre com os estipulado no regulamento, o que não sucede em nenhuma outra iniciativa municipal na região; iv) no MARF, a concepção e a estrutura das instalações edificadas permite a ocupação por módulos, agrupados ou desagrupados em função das necessidades das empresas.

Ou seja, estes dois casos, que não figuravam no PROT 1991 como os espaços estruturantes na região para o acolhimento empresarial - o MARF surge, posteriormente à sua consolidação, na Revisão do PROT (2007), e a área de Aljezur não é mencionada nesta revisão - acabam por praticamente ser os únicos casos em que houve uma concretização das orientações fornecidas pelos sucessivos enquadramentos estratégicos, embora estes mesmos enquadramentos tivessem apontado para outras localizações. Estes dois casos demonstram assim que a interpretação das orientações genéricas contidas nos documentos e planos estratégicos ficou ao livre arbítrio dos municípios (e dos privados). Demonstram igualmente que não tiveram lugar acções de monitorização, de acompanhamento e de avaliação da implementação das estratégias, caso contrário não resultariam apenas estas duas áreas que, nem figuravam no exercício de planeamento. Particularmente mais preocupante será porventura a evidência de que, com mais ou menos, e maiores ou menores, introduções no quadro legal e normativo, com frequentes redistribuições dos papéis e das competências das entidades, com planos mais ou menos físicos ou de natureza estratégica, em cada fase de novo quadro estratégico (não necessariamente com planeamento) persistam e se agravem as lacunas de base. De entre estas, a ausência de avaliação das anteriores directrizes e a extrema dificuldade em articular e operacionalizar as intervenções no território.

\section{Conclusões}

Como se procurou demonstrar ao longo do artigo, a melhor forma de aferir a qualidade das estratégias de desenvolvimento, assim como a eficiência da sua transposição para o território por via dos processos de planeamento será através da leitura e interpretação dos resultados expressos nesse mesmo território. Com 20 anos decorridos desde a aprovação das orientações emanadas do PROT 1991, mais de 15 desde a vigência da primeira geração de PDM na Região, já quatro anos desde a Revisão do PROT 2007 - 
embora ainda sem a segunda geração de planos directores - e, durante este período, diversos documentos de teor conceptual e estratégico que foram produzidos para enquadrar os planos regionais de ordenamento do território, estranhamente, ou não, o resultado que se tem no território não é o que se desejava. Como se afirmou nas primeiras páginas do artigo, deveria haver no território uma correspondência, quanto aos usos e funções, ao que está definido e previsto nas plantas de ordenamento dos PDM. Porém, muito poucas são as situações em que tal se verifica. A observação revela a manutenção e a perpetuação dos mecanismos de ocupação e apropriação do território que subsistem sem correspondência com os princípios do material estratégico, legislativo e normativo que foi sendo produzido.

Durante os últimos 20 anos, e não obstante: i) as sucessivas alterações dos quadros legais e normativos; ii) o alargamento dos âmbitos de elaboração, participação e concertação dos processos de planeamento e de ordenamento do território aos vários níveis e escalas geográficas de actuação das entidades; e iii) as significativas melhorias nos domínios tecnológicos, comunicacionais, informáticos, cartográficos, etc.; não se operaram as transformações desejadas e perspectivadas. Subsistem, e de forma bastante vincada, as "condicionantes de fundo" (Ferrão, 2004, pp. 74), apesar do novo quadro redistributivo das funções e responsabilidades de promoção do desenvolvimento territorial.

Em domínios como o objecto do presente artigo, são ainda evidentes os insuficientes desempenhos das funções de "regulação da acção de actores" (escalas nacionalregional) e, sobretudo, a "mobilização de actores regionais e subregionais em torno de programas de acção comuns" (Ferrão, 2004, pp. 76). A constituição e desenvolvimento de áreas para o acolhimento de actividades empresariais na Região do Algarve poderiam ter constituído um "programa de acção comum", tivesse entretanto existido nas várias fases do processo, um entendimento prospectivo dos diversos agentes envolvidos e, sobretudo, uma aproximação entre dois domínios que persistem em não se integrarem mutuamente: o desenvolvimento regional e o ordenamento do território.

Neste quadro, brevemente resumido, foram também apontados os exemplos da constituição das áreas empresariais de Aljezur e do MARF. Os documentos estratégicos de referência produzidos nos últimos 20 anos referem a necessidade de criação de áreas daquela natureza, que permitiriam criar e atrair empresas para a Região, e dotá-la de um tecido produtivo forte e gerador de emprego. Contudo, aqueles documentos não só não têm conseguido apresentar diagnósticos "reais" e, assim, uma fundamentação 
estruturada e consistente, como também não têm conseguido, naturalmente, mobilizar os restantes actores para a sua prossecução. Em 2012, ainda não teve lugar a formalização da revisão de nenhum PDM da Região, e os poucos processos em curso estão ainda numa fase muito embrionária; enquanto no quadro vigente continuam a subsistir as condições para as actuações "fragmentadas" e "localistas".

Por último, e face ao volume das "discordâncias" demonstradas ao longo do artigo entre os documentos estratégicos e enquadradores e o planeado, executado e ocupado, subsiste a questão da adequabilidade da área de localização empresarial enquanto figura para acolher as actividades empresariais. As discordâncias verificam-se um pouco por todo o país, não são um exclusivo do Algarve.

Os discursos e as hipóteses que suportam a concentração destas actividades em espaços e zonamento próprios referem um vasto leque de vantagens, nomeadamente: a diminuição dos custos com a infraestruturação; a especificidade da própria infraestruturação que não pode ser ubíqua e extensível a todo o território; o ambiente empresarial; as economias de escala, de aglomeração e as sinergias; a incompatibilização com outros usos; etc.. Parece, assim, com a concentração, prevalecer um quadro e uma lógica nos quais se combinam tanto as vantagens para as empresas (repartição de custos das infraestruturas, ambiente empresarial, e outros) como para o ordenamento do território e a gestão territorial. Até houve, como se deu conta, áreas empresariais que se constituíram neste contexto. Como foi destacado, apenas duas funcionam com uma gestão conjunta e com um projecto definido. Existem, porém, mais áreas na região, não exactamente nos parâmetros das duas referidas, mas aproveitando as vantagens próprias de uma aglomeração, mesmo que apenas orgânica.

Parece, assim, subsistir a adequabilidade da figura da área de localização empresarial. 0 que terá falhado, e sobre tal se procurou reflectir, terão sido: i) factores que estão na génese ou a montante do exercício de planeamento - orientações vagas, interpretações e aplicações das mesmas sem nexo, excesso de áreas de localização empresarial na grande maioria dos municípios, a escolha (e inscrição nos IGT) de localizações sem qualquer aptidão e viabilidade, etc.; ii) condições para implementação e monitorização eficaz dos IGT - a criação (frequentemente sem execução) de mais áreas, sem uma alteração (remoção, eventualmente) das existentes; a própria ultrapassagem, em muito, do período de 10 anos previsto na lei para a revisão do PDM, e iii) práticas, seguidas na gestão quotidiana em matéria de autorização de localização e licenciamento, que, sem uma perspectiva enquadradora, foram permitindo a instalação de unidades industriais, 
logísticas e comerciais um pouco por todo o território, frequentemente até em terrenos abrangidos por condicionantes especiais.

Entretanto, e como as empresas e as actividades nascem, desenvolvem-se e morrem, têm dinâmicas próprias que, frequentemente, apenas postumamente são enquadradas em modelos teóricos - funcionais, espaciais ou outros - e em quadros legais e normativos que, não raras vezes, requerem a aplicação de regimes transitórios para compatibilização (legalização), o processo de ocupação do território prossegue, em grande medida, no modelo que existia antes da cobertura do território pelos planos de ordenamento.

\section{Bibliografia}

CABRAL, J. e CRESPO, J. L. (2012) "Urban policy goals and territorial planning - articulations and lessons from planning urban regions in Porugal” in: Cravidão, F., Rio Fernandes, J. A. \& Valença, M. M. (Orgs.) Urban developments in Brazil and Portugal, New York: Nova Science Publishers

CEDRU (2000): Estudo de Avaliação do PROT Algarve (1989/96 - Relatório Final, Lisboa, Centro de Estudos em Desenvolvimento Regional e Urbano.

CCDR Algarve (2006): Estratégia de Desenvolvimento do Algarve 2007-2013, Faro, Comissão de Coordenação e Desenvolvimento Regional do Algarve

CCDR Algarve (2007): PROT Algarve: Volume I - Plano, Faro, Comissão de Coordenação e Desenvolvimento Regional do Algarve (também disponível em www.ccdr-alg.pt)

CCR Algarve (1990): Plano Regional de Ordenamento do Território do Algarve, Faro, Comissão de Coordenação Regional do Algarve

FERRÃO, J. (2004), “Uma política regional para Portugal”, Sociedade e Território, № 37/38, Junho 2004, pp. $72-79$

NEEDHAM, B. (2006) Planning, Law and Economics: The rules we make for using land, Routledge

PORTAS, N.; DOMINGUES, Á. e CABRAL, J. (2003) Políticas Urbanas - tendências, estratégias e oportunidades, Lisboa: Fundação Calouste Gulbenkian

PORTAS, N.; DOMINGUES, Á. e CABRAL, J. (2011) Políticas Urbanas II - transformações, regulação e projectos, Lisboa: Fundação Calouste Gulbenkian

SOARES, L. J. BRUNO (2004): "Paradoxos e equívocos de 20 anos de planeamento do território", Sociedade e Território, № 37/38, Junho 2004, pp. 96-102 